\title{
Investigation on growth of 15 blueberry varieties/strains in Qionglai
}

\author{
Yuxin Wang ${ }^{1 *}, K^{2} \mathrm{Xu}^{2}$, J in Wang ${ }^{3 *}$, Changjiang $\mathrm{Yi}^{4}$, Xun Wang ${ }^{3 \S}$ \\ ${ }^{1}$ College of Horticulture, Sichuan Agricultural University, Chengdu, Sichuan, China; 2 Sichuan Horticultural Crop \\ Agrotechnical Promotion Workstation, Chengdu, Sichuan, China; ${ }^{3}$ Institute of Pomology \& Olericulture, Sichuan \\ Agricultural University, Chengdu, Sichuan, China; ${ }^{3}$ Bureau of Agriculture and Forestry of J iangyang District, Luzhou, \\ Sichuan, China \\ *Co-first authors; \$C orresponding author: wangxun0104@ hotmail.com
}

\begin{abstract}
Blueberry is a kind of economic fruit with high nutritional value, good economic benefit and broad market prospect. In this experiment, the growth of 15 blueberry varieties/strains in Qionglai in Chengdu city was investigated. The results showed that the growth rate of 'Brigitta' and 'NBS2'was the best, the number of spindle branches increased by 5 in the half year of 'NBS2', and the height of 'Brigitta' increased by $15 \mathrm{~cm}$ in the half year. This experiment is expected to provide the reference data of suitable blueberry varieties in Qionglai city, which is of practical significance to the development of Sichuan blueberry industry.
\end{abstract}

Keywords: Blueberries. Varieties/strains; Growth; Sichuan Qionglai

\section{Introduction}

Blueberry (Vaccinium spp.) is a member of the rhododendron family bilberry subfamily bilberry plants, a deciduous perennial or evergreen shrub. Blueberry fruit is a fine graining, delicate flesh, sweet and sour palatability. The fruits are enriched in anthocyanins, a strong antioxidant substance can be anti-cancer and anti-aging, as well as organic acids and vitamins ${ }^{[1]}$. Blueberry plants are mainly divided into four types, i.e. shortbus, half highbush, highbush (northern highbush and southern highbush) and rabbiteye. The blueberries were different in tree size and tree shape. The height of rabbit eye blueberry tree can reach $10 \mathrm{~m}$. Highbush blueberries are 1-3 $\mathrm{m}$ high; the height of half highbush blueberries are $5-25 \mathrm{~cm}$; and the height of the shortbush blueberry trees are $30-50 \mathrm{~cm}^{[4]}$. The leaf length of different varieties of blueberry varies greatly. The leaf length of the dwarf blueberry bush is only about 1 $\mathrm{cm}$, while the leaf length of the tall blueberry bush can reach $8 \mathrm{~cm}$, and the leaf length of the rabbit eye blueberry is between the two ${ }^{[5]}$. In addition, the flowering period of blueberries in southern China is generally the first half of march, and the fruiting period of blueberries is two months after flowering, which is a typical summer fruit ${ }^{[6]}$. Commercial cultivation of blueberry in qionglai area started late and has not been long since then. Moreover, small-scale cultivation industry is not concentrated.As a new type of fruit, Blueberry, which has the reputation of “golden berry", will have an extremely wide development and utilization prospect in Qionglai city ${ }^{[14]}$.

\section{Materials and Methods}

1. Materials

Fifteen blueberry varieties/strains were 'O'Neil', 'Sweetheart', 'EM', 'Biloxi', 'Brigitta', 'Star', 'Pink lemonade', 'Sharpblue', 'Legacy', 'Elizabeth', 'Tifblue', 'Blomidon', 'NBS1', 'NBS2', 'NBS3'. Blueberry plants were all three-year plant, grown at the blueberry base in Qionglai city, Sichuan province. The orchard was at an altitude of $502 \mathrm{~m}$ in the region, warm and humid all year $16-18{ }^{\circ} \mathrm{C}$, annual average temperature, temperature of $10{ }^{\circ} \mathrm{C}$ or more sustained period of 240-280 d, accumulated temperature of 4000-6000 ${ }^{\circ} \mathrm{C}$, frost-free period of 230-340 d. Abundant rainfall, annual precipitation up to $1000-1200 \mathrm{~mm}$. 


\section{Growth indictor measurement}

Five plants in each variety/strain were selected to be observed. The observed time is from 2016 winter to the beginning of 2017, and the observation was conducted for four times, on October 21, 2016, December 5, 2016, March 28, 2017 and May 2017.

Observation indicators include: (1) Plant height: the distance was measured vertically from the base of the over ground main branch to the crown of the tree. (2) Stem thickness: two main axis branches were selected for each tree, and the diameter was measured with a vernier caliper $10 \mathrm{~cm}$ from the ground. (3) The number of spindle branches. (4) Some new ones. (5) Leaf length and width: 6 functional leaves were selected from annual branches of each tree for measurement.

\section{Results}

1. Plant height comparison

The plant height of 15 blueberries is shown in Fig. 1. The height of 'Tifblue' reaches $1 \mathrm{~m}$. The 'Pink lemonade', 'Legacy' plant is more than $80 \mathrm{~cm}$ high. 'Bilox', 'Pink lemonade' and 'NBS3' grew by more than $10 \mathrm{~cm}$. 'Brigitta', 'Legacy', increased by nearly $20 \mathrm{~cm}$. The height of plants in 'Blomidon' is only about $40 \mathrm{~cm}$, while the height of plants in 'Blomidon' and 'EM' is only 2 to $3 \mathrm{~cm}$. The plant height of most plant species is not obvious.

\section{Thick stems comparison.}

The comparison of stem diameter of 15 varieties is shown in Fig. 2. It can be seen from Fig. 2 that the stem thickness of 'Pink lemonade' reached $8 \mathrm{~mm}$ when the fourth measurement was made, And it may because the spindle branch was heavily lignified. All plants had stems about $5 \mathrm{~mm}$ thick. 'Sweetheart', 'Pink lemonade', 'NBS3', 'NBS2', and 'Tifblue' stem thickness increased more than $1 \mathrm{~mm}$; The stem of 'EM' was only 5 $\mathrm{mm}$ thick. The overwintering period between the second and third times was largely unmarked.

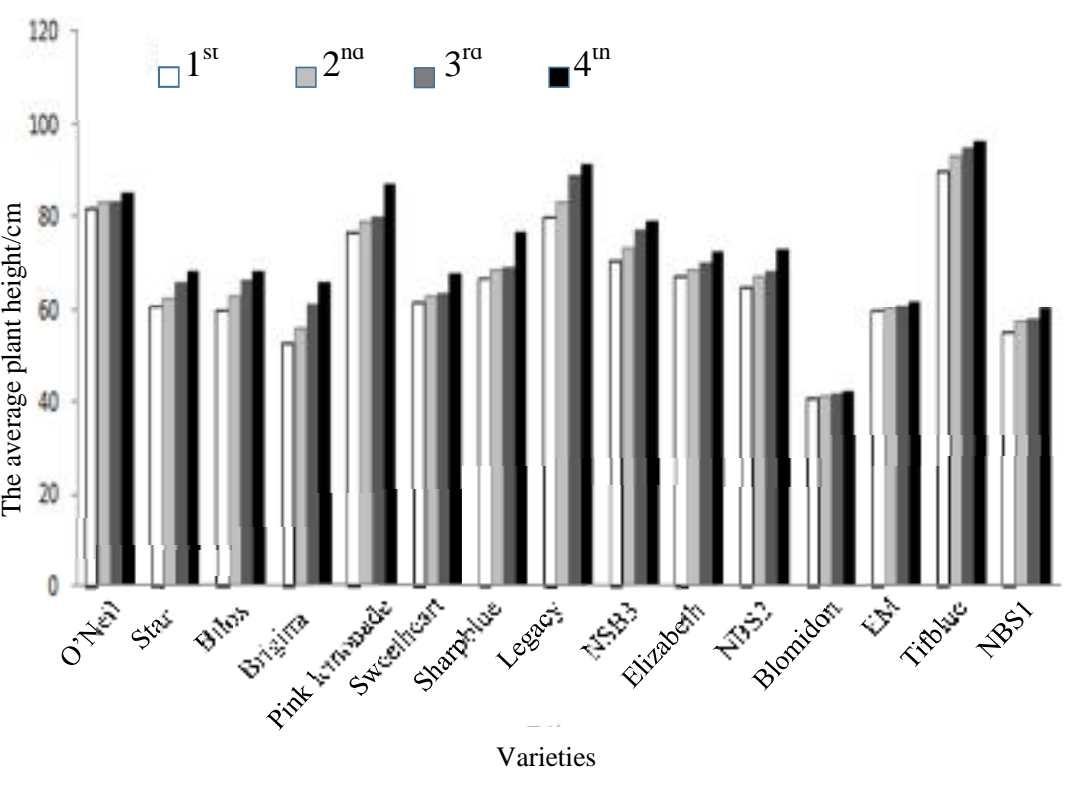

Fig. 2

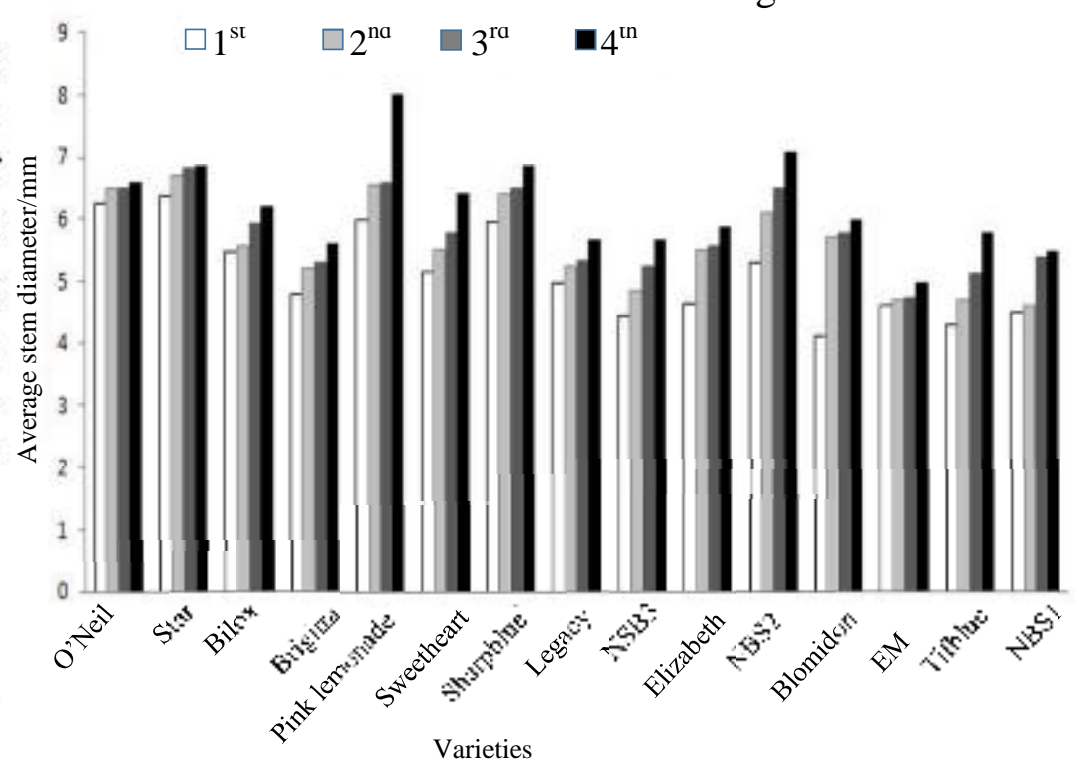

Fig. 3 
3. Principal axis branch number comparison.

The number of spindle branches of 15 kinds of blueberries was compared as shown in Fig. 3. As can be seen from Fig. 3, the spindle branches of 'Brigitta', 'NBS2', 'EM', and 'Elizabeth' increased more. 'NBS2' spindle branches increased by up to 5; 'EM', 'Tifblue' spindle branch increased slightly less than 'NBS2' for about 4 branches; The number of spindle branches of 'O'Neil', 'Sweetheart', 'Sharpblue' and 'Blomidon' did not increase. 'Pink lemonade', 'Elizabeth' the number of

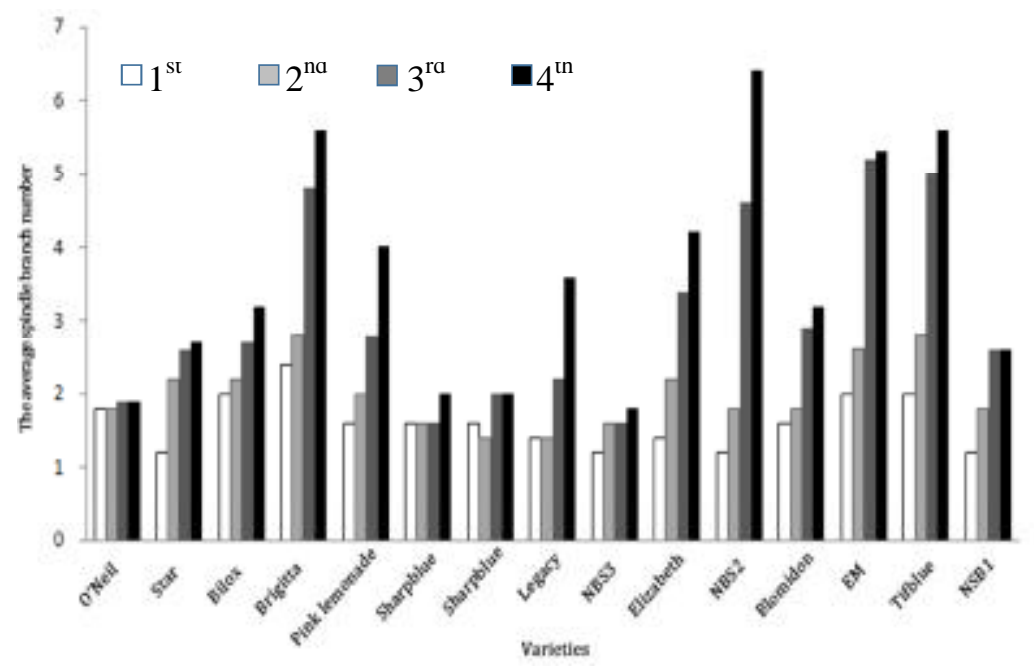
spindle branches increased by 2; 'Star' and 'Blomidon' only added about 1 branch. Most spindle branches increased during the third and fourth observations.

4. Comparison of the number of new shoots A comparison of the new shoots number of 15 blueberries is shown in Fig. 4. It can be seen from Fig. 4, the new shoots of 'Pink lemonade', 'Brigitta', and 'NBS2' grew relatively good, and the new shoots numbers of 'NBS2' was especially prominent. The number of new shoots of 'Brigitta' was close to three in the first and second observation. 'Pink lemonade', 'Biloxi', 'Legacy', and 'NBS2', on the

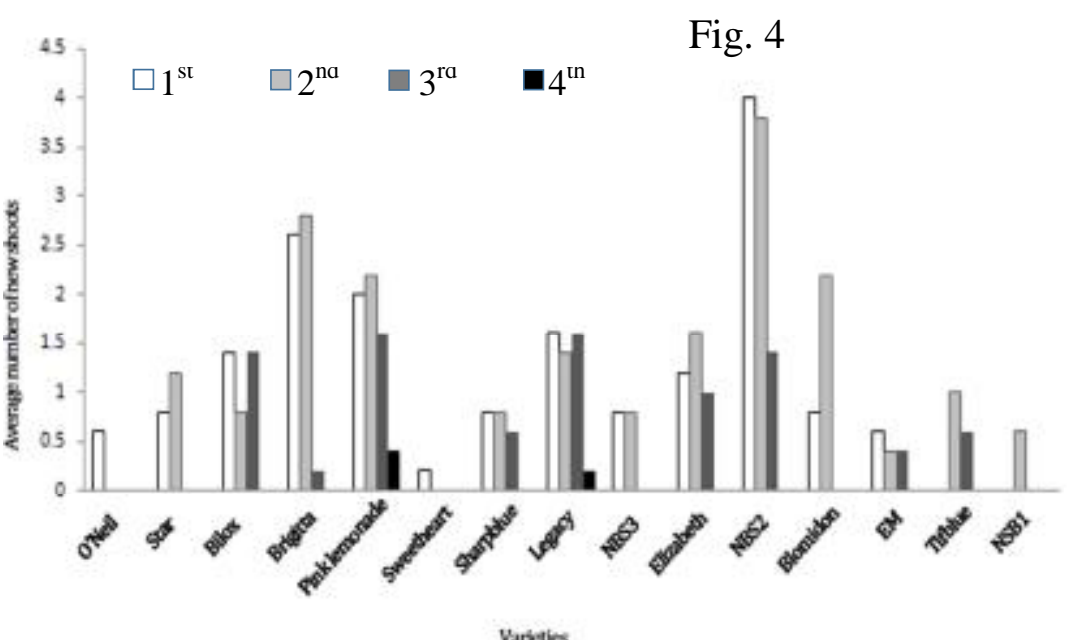
third observation, most of the plants had more than one new shoots. Other varieties are very different from the first three varieties, including 'Star', 'Sharpblue', 'NBS3', 'EM'. The average number of new shoots of 'Tifblue' was less than one, which means that many strains did not have new shoots. At the fourth measurement, only part of 'Pink lemonade' and 'Legacy' had new shoots.

\section{Leaf characteristics}

The leaf length comparison of 13 kinds of blueberries is shown in Fig. 5. It can be seen from Fig. 5, the leaf length of most varieties was about $4 \mathrm{~cm}$. 'Brigitta', 'Elizabeth', and 'NBS2', even reached $6 \mathrm{~cm}$ in length. The leaves of 'NBS2' were the longest in all varieties. The leaf length of 'Sweetheart' was less than $3 \mathrm{~cm}$ at the time of measurement. The leaves of 'NBS3' and 'Tifblue' are only $1 \mathrm{~cm}$ longer than those of 'Sweetheart'. The leaf width of 15 kinds of blueberries is compared as shown in Fig. 6. It can be seen from Fig. 6, the leaves of 'Elizabeth' and 'Brigitta' were about $3 \mathrm{~cm}$ in width, and the longest one was over $3 \mathrm{~cm}$. The minimum width of 'Sweetheart' is just over $1 \mathrm{~cm}$. 'Star', 'Bilox', 'Pink lemonade', 'Sharpblue', 'Legacy', and 'Tifblue', their leaves were about $2 \mathrm{~cm}$ in width. 'Brigitta', 'NBS2' leaves are nearly $3 \mathrm{~cm}$ in width. No plants with particular long leaf widths were found, and short leaf widths may also be caused by the different variety. 
Fig. 5

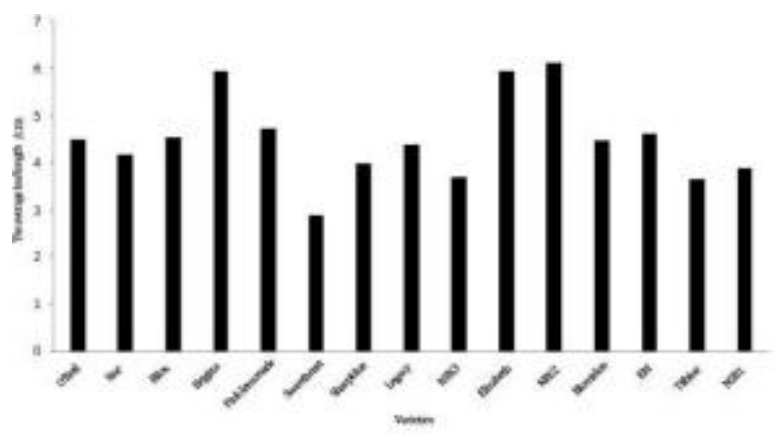

Fig. 6

\section{Discussion}

'NBS2' performed best among all varieties/strains inform growth indicators data. The small number of fruiting pendants also indicated that this variety has a serious growth deficit in the current environment, leading to a serious lag in reproductive growth. Previous research indicated that the plant growth environment would suffer from excessive water content and insufficient nutrients ${ }^{[15]}$. Therefore, it can be suggested to increase the existing fertilizer and substrate moisture content in order to bring better results to this variety.

The growth indicators data of 'Stars', 'Legacy', 'Sharpblue' were comparable with the experiment performed in Shanxi, in which the blueberry plants were $10-15 \mathrm{~cm} \mathrm{high}^{[16]}$. Somewhat differently, when compared to the results of the experiment performed in Fuyang, Zhejiang region, the plant height and spindle branch number were relatively low, suggesting that need longer test data to determine the growth adaptability. Two varieties, 'Brigitta' and 'O'Neil', obtained lower plant height and less number new shoots than that in Xu's experiment ${ }^{[17]}$. Both Qionglai, Sichuan and Fuyang, Zhejiang locate in similar latitudes, but different longitudes. The general environments of two locations are similar but are different in microclimate, which might result in the differences in blueberry plant growth indicators. . In the experiment in Guilin ${ }^{[18]}$, the result showed "Biloxi" was poorly growing.

\section{References}

[1] Ehlenfeldt MK, Prior RL. Oxygen radical absorbance capacity (ORAC) and phenolic and anthocyanin concentrations in fruit and leaf tissues of highbush blueberry. Journal of Agricultural and Food Chemistry, 2001, 49(5): 2222-7.

[2] Gu X, He SA, Yu H, et al.. Blue berries and cranberries. Beijing: China agricultural press, 2001.

[3] Kader F, Rovel B, Girardin M, et al.. The Fractionation and identification of the phenolic come of highbush blueberries ( Vaccinium corymbosum, L.). Journal of Food Chemistry, 1996, 55 (1) : 35-40.

[4] Sun GB. Research on the botanical characteristics of blueberries. Tianjin agroforestry technology, 2014, 67(5): 39-41

[5] Chang FL, Zheng WX, Han C. Biological characteristics and health effects of blueberries and their market prospects. Heilongjiang agricultural science, 2013, 36(2): 160-161.

[6] Shang XF. Biological characteristics and cultivation techniques of blueberries. Modern agricultural science and technology, 2010, 39(2): 135-137.

[7] Li J, Sun SX, Chen D, et al.. Production status and development Suggestions of sichuan blueberry. Sichuan agricultural science and technology, 2013, 43(9): 7-8.

[8] Ma MW. Fruit tree growth and prevention measures. China agricultural reclamation, 1996, 46(11): 32.

[9] Mao PJ. Introduction experiment of different varieties of blueberries in Shanxi province. Yang L: northwest agricultural and forestry university, 2016.

[10] Xu J, Wang QH, Qian LP, et al.. Preliminary report on pilot planting of 7 blueberry varieties in fuyang. Zhejiang agricultural science, 2017, 58(11): 1916-1917.

[11] Zhang D, Zhong K, Zhou YX, et al.. Introduction selection and cultivation technology test of 7 blueberry varieties. Fruit trees of southern China, 2017, 46(05): 139-141. 